\title{
MASTITE E SÍNDROME DA QUEDA DO LEITE / INFECÇÃO POR Leptospira interrogans EM OVELHAS DA RAÇA SANTA INÊS NO DISTRITO FEDERAL
}

\author{
Adriana Helena Rosa ${ }^{1}$, Luiza de Souza SeiXas ${ }^{1}$, CONCEPta Margaret MCMANus Pimentel ${ }^{2}$, \\ RÔMUlo CERQueIRA LEITE ${ }^{3}$, Élvio CARLOS MOREIRA ${ }^{3}$, CRISTIANO BARROS DE MELO ${ }^{4}$ \\ ${ }^{1}$ Pós-graduandos da Universidade de Brasília, Brasília, DF, Brasil. \\ ${ }^{2}$ Professora Doutora da Universidade Federal do Rio Grande do Sul, Porto Alegre, RS, Brasil \\ ${ }^{3}$ Professor Doutor da Universidade Federal de Minas Gerais, Belo Horizonte, MG, Brasil. \\ ${ }^{4}$ Professores Doutores da Universidade de Brasília, Brasília, DF, Brasil. Email: cristianomelo@unb.br
}

O presente trabalho foi realizado com o objetivo de estudar a relação entre a mastite clínica e a infecção por Leptospira interrogans / síndrome da queda do leite em ovelhas da raça Santa Inês. Examinaram-se 1000 ovelhas, em 12 fazendas do Distrito Federal, quanto à sua condição clínica, com o objetivo de detectar animais com mastite clínica. Considerando um estudo de caso controle, os animais foram divididos em dois grupos: aqueles que apresentavam sinais de mastite clínica (G1) e os que não apresentavam sinais de mastite clínica (G2). Colheram-se amostras de sangue das ovelhas dos dois grupos e utilizouse o teste de soroaglutinação microscópica para identificar aquelas soropositivas para Leptospira spp. Dos animais do primeiro grupo, quatro $(4,08 \%)$ foram soropositivos para Leptospira spp, sendo três positivos para as sorovariedades Hardjoprajitno (Norma) e Hardjoprajitno (OMS) e um animal positivo para as sorovariedades Australis e Autumnalis. Dos animais do segundo grupo, dois $(5,26 \%)$ foram soropositivos, ambos para as sorovariedades Hardjoprajitno (Norma) e Hardjoprajitno (OMS). Não foi observada relação entre a síndrome da queda do leite / infecção por Leptospira spp e a presença de mastite clínica nas ovelhas ( $\mathrm{p}>0,05)$.

PALAVRAS-CHAVE: Doença; infecção; ovino; saúde animal.

\section{MASTITIS AND MILK DROP SYNDROME / Leptospira interrogans INFECTION IN SANTA INES EWES FROM DISTRITO FEDERAL}

\section{ABSTRACT}

The aim of the present work was to determine the relationship between clinical mastitis and Leptospira interrogans / Milk Drop Syndrome in Santa Inês ewes. One thousand sheep were examined on 12 farms in the Distrito Federal, Brazil, as to their clinical condition, in order to identify animals with clinical mastitis. The animals were divided into two groups: animals which presented clinical mastitis symptoms (G1) and animals which did not have clinical mastitis symptoms (G2). Blood samples were collected from all ewes of the two groups. The microscopic agglutination test was performed

in order to identify the seropositive animals to Leptospira spp. Four (4.08\%) animals of the first group were seropositives to Leptospira spp., of which three were positives to Hardjoprajitno (Norma) and Hardjoprajitno (OMS) sorovars and one to both Australis and Autumnalis sorovars. In the second group, two $(5.26 \%)$ animals were seropositives to both Hardjoprajitno (Norma) and Hardjoprajitno (OMS) sorovars. A relationship between Leptospira spp. infection / milk drop syndrome and the presence of clinical mastitis in ewes $(p>0.05)$ was not observed.

KEYWORDS: Animal health; disease; infection; sheep. 


\section{INTRODUÇÃO}

Episódios de mastite em ovinos têm sido a principal razão de abate ou morte precoce de ovelhas por problemas sanitários (MALHER et al., 2001; BERGONIER et al., 2003; LEITNER et al., 2008, MELO et al., 2008). Pesquisas demonstraram que as consequências deletérias da mastite são mais significativas em pequenos ruminantes do que em vacas leiteiras (LEITNER et al., 2004a).

Em pequenos ruminantes, uma consistente redução da produção de leite, seguida de infecções na glândula mamária, tem sido descrita com várias intensidades, dependendo do envolvimento de uma ou ambas as glândulas. Quando há envolvimento de ambas as glândulas, relatou-se uma redução de 58\% e $30 \%$ na produção leiteira de ovinos e caprinos, respectivamente (TORRES-HERNADEZ \& HOHENBOKEN, 1979; McCARTHY et al., 1988; GONZALO et al., 1994; CUCCURU et al., 2002; LEITNER et al., 2003, 2004a,b).

$\mathrm{O}$ risco de mastite clínica é maior em ovelhas que têm gestação tripla, quando comparadas aquelas que têm gestação simples ou gemelar com apenas dois cordeiros e a porcentagem de mortalidade entre ovelhas durante a lactação é significativamente superior nas que apresentam mastite clínica. Além disso, a mortalidade de cordeiros também é superior quando as mães apresentam mastite clínica. A mastite causada por Leptospira spp. é uma importante causa de morte de matrizes ovinas após o primeiro parto. É observada uma agalactia aguda que frequentemente leva à morte de cordeiros por inanição (FAINE et al., 1999; ARSENAULT et al., 2008).

Ovinos não são hospedeiros naturais para $L$. Hardjo e geralmente apresentam infecções de curta duração, mas com efeitos patológicos severos. Epidemias de agalactia em rebanhos ovinos, a síndrome da queda do leite, têm sido associadas com infecção por $L$. Hardjo. Pouco tem sido descrito sobre essa síndrome em rebanhos ovinos (RADOSTITS et al., 2007; MELO et al., 2010).

Considerando a alta ocorrência de mastite em ovelhas Santa Inês, bem como os poucos estudos sobre a infecção por Leptospira e sobre a síndrome da queda do leite em ovelhas, este trabalho tem o objetivo de estudar casos de mastite clínica e a sua relação com a infecção por Leptospira sp e com a síndrome da queda do leite em ovelhas em rebanhos no Distrito Federal.

\section{MATERIAL E MÉTODOS}

O presente trabalho foi realizado no período de janeiro a maio de 2007, avaliando-se todas as ovelhas pertencentes aos rebanhos ovinos da raça Santa Inês localizados em 12 fazendas no Distrito Federal (Vargem Bonita, Planaltina e Recanto das Emas), compreendendo um total de 1000 animais avaliados nas 12 fazendas. Todas as ovelhas foram examinadas clinicamente como proposto por CALAVAS et al. (1998), visando detectar ovelhas com mastite clínica, sendo que as glândulas mamárias foram observadas, palpadas e comparadas umas com as outras, suas formas, tamanho e consistência, e as anormalidades descritas.

Do total de animais avaliados por exame clínico detalhado, realizou-se um estudo de caso controle (THRUSFIELD, 2004), para isso foram separadas 136 ovelhas, que compuseram dois grupos, sendo: G1 - animais que apresentavam sinais de mastite clínica (n=98); e G2 - animais que não apresentavam sinais de mastite clínica - grupo controle $(n=38)$, conforme SAMPAIO (1998). Em seguida, colheu-se o sangue com frascos a vácuo (Vacutainer ${ }^{\circledR}$ ) de todas as ovelhas dos dois grupos, separando-se o soro, aliquotando-o e armazenando-o $\mathrm{a}-20^{\circ} \mathrm{C}$ até posterior análise.

Visando descrever fatores predisponentes e inferir sobre o perfil sanitário dos estabelecimentos produtores, bem como as características observadas nos úberes, tetas, secreção mamária, estado geral de cada animal amostrado, histórico reprodutivo, idade estimada por cronologia dentária, conforme o preconizado por NSW AGRICULTURE (2003), entre outros, foi aplicado um formulário de inquérito dos rebanhos e dos animais amostrados, permitindo avaliar as técnicas de manejo utilizadas nas propriedades.

Realizou-se o teste de soroaglutinação microscópica, o qual consiste na identificação de animais soropositivos para leptospirose, utilizandose como antígenos leptospiras vivas, provenientes de culturas de cepas-padrão, mantidas por repiques semanais em meio líquido de Stuart, Ellinghausen ou similar, seguindo descrições de GALTON et al. (1965) e RYU (1970), frente a uma bateria de 14 sorogrupos (australis, autumnalis, ballum, bataviae, butembo, canicola, grippothyphosa, hebdomadis, icterohaemorrhagiae, mini, pomona, pyrogenes, sejroe e tarassovi) e 21 sorovariedades de Leptospira (Australis, Bratislava, Autumnalis, Ballum, Bataviae, Brasiliensis, Butembo, Canicola, Grippothyphosa, Hebdomadis, Icterohaemorrhagiae, Szwajizak, Mini, Pomona, Pyrogenes, Hardjoprajitno (OMS), Hardjoprajitno (Norma), Hardjo (hardjobovis), Wolffi, Sejroe e Tarassovi. 
O critério adotado para leitura das reações positivas nos soros foi a diluição de 1:100, cujo campo microscópico apresentasse $50 \%$ ou mais de leptospiras aglutinadas, sendo as análises realizadas no Laboratório de Zoonoses do Departamento de Medicina Veterinária Preventiva, na Escola de Veterinária da Universidade Federal de Minas Gerais, em Belo Horizonte, Minas Gerais.

$\mathrm{O}$ teste de soroaglutinação microscópica ocorreu em duas etapas: triagem e titulação. A etapa de triagem consistiu na diluição do soro a 1:50 $(0,2$ $\mathrm{mL}+9,8 \mathrm{~mL}$ ) em tampão fosfato-salino (PBS Phosphate Buffered Saline) de pH 7,2. Em seguida, distribuiu-se $0,2 \mathrm{ml}$ da diluição em placas, nas quais foram acrescentados $0,2 \mathrm{~mL}$ de suspensão antigênica correspondente. Nessa etapa, a diluição final do soro passou a ser 1:100. Após agitação e repouso em temperatura ambiente por duas horas, as placas foram analisadas em microscópio com condensador de campo escuro, com objetiva 10x e ocular 10 a 16x, adotando-se o grau de aglutinação de $1+$ a 4+ para cada antígeno, conforme os critérios abaixo:

Negativo= ausência de aglutinação, com $100 \%$ de leptospiras livres;

$1+=$ presença de aglutinação, com $75 \%$ de leptospiras livres; *

$2+=$ presença de aglutinação, com $50 \%$ de leptospiras livres;

$3+=$ presença de aglutinação, com $25 \%$ de leptospiras livres;

$4+=$ presença de aglutinação e abaixo de $25 \%$ de leptospiras livres.

*O soro com aglutinação em grau 1+ também foi considerado negativo.

Os soros que, na prova de triagem, apresentaram redução no número de leptospiras livres na ordem de 50\% a $100 \%$ foram submetidos à prova de titulação.

A partir da diluição 1:50 da prova de triagem, foram preparadas mais nove diluições consecutivas do soro (títulos de 1:100 a 1:25600), distribuídas em placas. Em seguida acrescentou-se $0,2 \mathrm{~mL}$ do antígeno aos poços da respectiva fileira da placa. Nessa etapa as diluições do soro passaram a ser de 1:100 a 1:51200. Após a incubação foi realizada a leitura conforme descrito para prova de triagem, considerando-se como ponto final de reação a mais alta diluição do soro capaz de aglutinar ou "lisar" $50 \%$ ou mais leptospiras.

Os dados foram analisados por meio do "Statistical Analysis System" (SAS, 1999), utilizando-se o teste de Qui-quadrado.

\section{RESULTADOS E DISCUSSÃO}

Com relação à idade, em ambos os grupos os animais com quatro mudas representaram a maioria (72,5\% no G1 e 39,5\% no G2) (Tabela 1). Esse fato colabora para uma maior ocorrência de mastite, pois, quanto mais velhos os animais, maior a exposição aos fatores de risco (ARSENAULT et al., 2008).

TABELA 1. Faixa etária dos animais do G1 e G2

\begin{tabular}{ccc}
\hline Faixa etária & $\mathrm{N}^{\mathrm{o}}$ de animais $-\mathrm{G} 1$ & $\mathrm{~N}^{\mathrm{o}}$ de animais $-\mathrm{G} 2$ \\
\hline 1 muda=12 a 19 meses* $^{*}$ & 5 & 4 \\
2 mudas $=18$ a 24 meses & 7 & 9 \\
3 mudas $=23$ a 36 meses* & 12 & 10 \\
4 mudas $=28$ a 48 meses* & 71 & 15 \\
Sem dentes $=>48$ meses & 1 & 0 \\
Sem Informação & 2 & 0 \\
Total & 98 & 38 \\
\hline
\end{tabular}

* NSW AGRICULTURE (2003)

As alterações de úbere observadas com mais frequência no G1 foram endurecimento $(43,8 \%$, $\mathrm{n}=43)$ e fibrosamento $(18,4 \%, \mathrm{n}=18)$ (Tabela 2). O endurecimento do úbere pode indicar presença de mastite clínica aguda e o fibrosamento, de mastite clínica crônica (MELO et al., 2008). Com relação às características de linfonodos mamários, no G1 73,5\% $(n=72)$ dos animais não apresentaram alterações e em 68,4\% (n=67) dos animais não se observou alteração na secreção mamária (Tabela 3).

No G1, 10 ovelhas $(10,2 \%)$ eram multíparas e os proprietários não souberam informar o histórico reprodutivo de 57 animais $(58,2 \%)$. No G2, ao contrário do G1, apenas seis ovelhas $(15,8 \%)$ eram multíparas (Tabela 4). Vários autores descreveram um aumento na ocorrência de mastite em ovelhas 
relacionado ao número de lactações (parições) BERGONIER \& BERTHELOT, 2003).

(KIRK et al., 1980; FTHENAKIS, 1994;

TABELA 2. Características do úbere observadas nos animais do G1

\begin{tabular}{lc}
\hline Características do úbere & $\mathrm{N}^{\circ}$ de animais - G1 \\
\hline Úbere Endurecido & 43 \\
Glândula Direita Perdida & 7 \\
Glândula Esquerda Perdida & 10 \\
Perda de Úbere & 5 \\
Úbere Fibrosado & 18 \\
Úbere Atrofiado & 6 \\
Mastite Clínica & 3 \\
Sem Informação & 6 \\
Total & 98 \\
\hline
\end{tabular}

TABELA 3. Características da secreção mamária observada no G1

\begin{tabular}{lc}
\hline Tipo de secreção mamária & $\mathrm{N}^{\circ}$ de animais - $\mathrm{G} 1$ \\
\hline Purulenta & 22 \\
Serosa & 2 \\
Sanguinolenta & 4 \\
Amarelada & 2 \\
Grumos & 1 \\
Sem Alteração & 67 \\
Total & 98 \\
\hline
\end{tabular}

A literatura sobre mastite ovina no Brasil é limitada. Entretanto, estudos em diferentes partes do mundo têm sido conduzidos para avaliação da ocorrência de infecções da glândula mamária de ovinos. A maioria desses estudos utiliza cultura microbiana como um fator determinante para casos clínicos de mastite ou "California Mastitis Test" (CMT) e a Contagem de Células Somáticas (CCS) como indicadoras de ocorrência de mastite subclínica em ovelhas lactantes (LAFI et al., 1998).

TABELA 4. Histórico reprodutivo dos animais dos grupos G1 e G2

\begin{tabular}{lcc}
\hline Histórico reprodutivo & $\mathrm{N}^{\mathbf{o}}$ de animais - G1 & $\mathrm{N}^{\mathbf{o}}$ de animais - G2 \\
\hline Multípara & 10 & 6 \\
Cordeiro ao pé & 13 & 2 \\
Primípara & 5 & 2 \\
Gestante & 8 & 0 \\
Intervalo de parto aumentado & 4 & 3 \\
Aborto & 1 & 2 \\
Sem Informação & 57 & 23 \\
Total & 98 & 38 \\
\hline
\end{tabular}

Do total de ovelhas analisadas, $9,8 \%$ apresentaram sinais de mastite clínica, sendo uma ocorrência alta quando comparada à encontrada por outros autores em outros países. CALAVAS et al. (1998) analisaram uma média de 245 ovelhas por rebanho em 78 rebanhos do sul da França, em que foram examinadas todas em fase de lactação. A ocorrência de mastite clínica observada foi de 4,51\%. SARATSIS et al. (1998) examinaram 3.367 ovelhas de rebanhos da Grécia no final do período de lactação e no período seco e encontraram $5,1 \%$ de mastite, verificando que o risco de uma ovelha desenvolver alguma anormalidade no úbere na fase 
inicial de involução mamária foi o mesmo que no período seco.

Em um estudo realizado em Quebec, no Canadá, com rebanhos ovinos de corte durante período de lactação (58 dias), ARSENAULT et al. (2008) detectaram incidência de 0 a 6,6 casos de mastite clínica a cada 100 lactações, com uma média de 1,2. O risco de mastite clínica observado foi significativamente associado com a região e o número de cordeiros paridos. Ovelhas que pariram três cordeiros tiveram significativamente mais risco de apresentar mastite clínica do que as que tiveram gêmeos ou apenas um cordeiro.

Resultados semelhantes a este trabalho foram observados por GROSS et al. (1978), que relataram incidência de mastite clínica de 10 casos a cada 100 ovelhas. No Brasil, em um surto descrito no Rio Grande do Sul, de 80 ovelhas examinadas, $10 \%$ apresentaram mastite clínica e 8,75\% fibrose da glândula mamária (FERNANDES \& CARDOSO, 1985).

Provavelmente, a alta ocorrência de mastite clínica observada nos rebanhos ovinos estudados deve-se ao fato de a ovinocultura ainda ser uma atividade recente no Distrito Federal, onde as instalações e o manejo ainda são inadequados pela falta de experiência e correta instrução técnica dos produtores.

Dos animais pertencentes ao $\mathrm{G} 1(\mathrm{n}=98)$, que apresentavam sinais de mastite clínica, apenas quatro (4,08\%) foram soropositivos para Leptospira spp, apresentando títulos de 1:100 e 1:200, sendo três animais positivos para os sorovares Hardjo Amostra Norma e Hardjo (OMS) e um animal positivo para os sorovares Australis e Autumnalis. Dos animais pertencentes ao G2 $(n=38)$, que não apresentavam sinais de mastite clínica, apenas dois $(5,26 \%)$ foram soropositivos para Leptospira spp, apresentando títulos de 1:100 e 1:400, sendo os dois animais positivos para as sorovariedades Hardjo Amostra Norma e Hardjo (OMS). Os únicos sorovares encontrados foram Hardjo Amostra Norma, Hardjo (OMS), Australis e Autumnalis, sendo que todos os animais estavam positivos para dois sorovares simultaneamente. Os sorotipos Hardjo Amostra Norma e Hardjo (OMS) foram encontrados com maior frequência neste estudo, em cinco animais, com prevalência de $83,3 \%$, sendo que Australis e Autumnalis foram encontrados em apenas um animal, com prevalência de $16,7 \%$. Nenhum dos animais amostrados apresentava sinais clínicos de leptospirose, apesar de a sorovariedade Hardjo, com certa frequência, causar sinais clínicos mais severos, como transtornos reprodutivos, natimortos e crias fracas (ELLIS et al., 1983).
Estudos realizados em outros países também indicaram o sorovar Hardjo como o mais prevalente entre ovinos. Na Turquia, os sorovares Hardjo e Grippotyphosa foram os mais prevalentes (TURKUTANIT et al., 2002; SAGLAM et al., 2008).

O grande número de animais afetados por sinais clínicos de mastite provavelmente pode ser explicado pelo precário sistema de criação observado nas propriedades, uma vez que a ovinocultura no Distrito Federal encontra-se em expansão, mas de forma desordenada, sem domínio do conhecimento e das técnicas necessárias para um bom sistema de produção.

Apesar de não ter sido encontrada relação entre mastite e síndrome da queda do leite / infecção por Leptospira interrogans em ovelhas neste estudo, é importante que sejam realizadas no Brasil mais pesquisas que envolvam o estudo da relação entre a mastite e a síndrome da queda do leite em ovinos, pois pouco tem sido relatado a respeito desta enfermidade nessa espécie, o que pode trazer grandes perdas para os produtores e para a economia nacional, já que a ovinocultura está em crescimento e adquirindo grande importância no mercado, principalmente na região Centro-Oeste.

\section{CONCLUSÕES}

Conforme os resultados observados e o teste estatístico realizado, não foi verificada diferença significativa entre os resultados dos dois grupos, demonstrando que, neste trabalho, não houve relação entre a síndrome da queda do leite / infecção por Leptospira spp e a presença de mastite clínica nas ovelhas.

\section{AGRADECIMENTOS}

Ao CNPq (Edital 27/2007), CNPq - Bolsas PQ e ao CNPq/INCT-Pecuária pelas bolsas, a CAPES/Procad Novas Fronteiras 2007 pelo financiamento da estada das alunas no Laboratório de Zoonoses na UFMG. A Camila Braz Ribeiral, Ricardo Luz e a EMATER-DF, pelo suporte no trabalho realizado nas fazendas.

\section{REFERÊNCIAS}

ARSENAUlT, J., DUBREUIL, P., HIGGINS, R., BÉLANGER, D. Risk factors and impacts of clinical and subclinical mastitis in commercial meat producing sheep flocks in Quebec, Canada. Preventive Veterinary Medicine, n. 87, v. 3-4, p. 373-393, 2008. 
BERGONIER, D.; BERTHELOT, X. New advances in epizootiology and control of ewe mastitis. Livestock Production Science, v.79, p. 1-16, 2003.

BERGONIER, D., DE CREMOUX, R., RUPP, R., LAGRIFFOUL, G., BERTHELOT, X. Mastitis of dairy small ruminants. Veterinary Research, v. 34, p. 689$716,2003$.

CALAVAS, D., BUGNARD, F., DUCROT, C., SULPICE, P. Classification of the clinical types of udder disease affecting nursing ewes. Small Ruminant Research, v. 29, p. 21-31, 1998.

CUCCURU, C., PRETI, C., MELONI, M.G., MORONI, P. Riduzione delle cellule somatiche nella specie ovina. Obiettivi \& Documenti Veterinari, n. 1, v. 23, p. 21-26, 2002.

ELLIS, W.A., BRYSON, D.G., NEILL, S.D., MCPARLAND, P.J., MALONE, F.E. Possible involvement of leptospires in abortion, stillbirths and neonatal deaths in sheep. Veterinary Record, v. 112, p. 291-293, 1983.

FAINE, S., ADLER, B., BOLIN, C., PEROLAT, P. Leptospira and Leptospirosis. 2.ed. Medical Science: Melbourne, Australia, 1999. 272 p.

FERNANDES, J. C. T.; CARDOSO, M. R. I. Mamite ovina causada por Staphylococcus aureus. Primeira observação no Brasil. Arquivos da Faculdade de Veterinária da UFRGS, v. 13, p. 71-74, 1985.

FTHENAKIS, G.C. Prevalence and etiology of subclinical mastitis in ewes of southern Greece. Small Ruminant Research, v. 13, p. 293-300, 1994.

GALTON, M.M., SULZER, R.C., SANTA ROSA, C.A., Fields, M.F. Application of microtechnique to the agglutination test for Leptospiral antibodies. Applied Microbiology,v. 13, p. 81-85, 1965.

GONZALO, C., CARRIEDO, J.A., BARO, J.A., PRIMITIVO, F.S. Factors influencing variation of test day milk yield somatic cell count, fat, and protein in dairy sheep. Journal of Dairy Science, v. 77, p. 1537-1542, 1994.

GROSS, S.J., POLLACK, E.J., ANDERSON, J.G., TORELL, D.T. Incidence and importance of subclinical mastitis in sheep. Journal of Animal Science, v. 46, p. 1, 1978.

KIRK, J.H., HUFFMAN, E.M., ANDERSON, B.C. Mastitis and udder abnormalities as related to neonatal lamb mortality in shed-lambed range ewes. Journal of Animal Science, v. 50 n. 4, p. 610-616, 1980.

LAFI, S.Q., AL MAJALI, A.M., ROUSAN, M.D., ALAWNEH, J.M. Epidemiological studies of clinical and subclinical ovine mastitis in Awassi sheep in northern Jordan. Preventive Veterinary Medicine, v. 33, p. 171$181,1998$.

LEITNER, G., CHAFFER, M., CARASO, Y., EZRA, E., KABABEA, D., WINKLER, M., GLICKMAN, A.,
SARAN, A. Udder infection and milk somatic cell count, NAGase activity and milk composition - fat, protein and lactose - in Israeli-Assaf and Awassi sheep. Small Ruminant Research, v. 49, p. 157-164, 2003.

LEITNER, G., CHAFFER, M., SHAMAY, A., SHAPIRO, F., MERIN, U., EZRA, E., SARAN, A., SILANIKOVE, N. Changes in milk composition as affected by subclinical mastitis in sheep. Journal of Dairy Science, v. 87, p. 46-52, 2004a.

LEITNER, G., MERIN, U., SILANIKOVE, N. Changes in milk composition as affected by subclinical mastitis in goats. Journal of Dairy Science, v. 87, p. 1719-1726, 2004b.

LEITNER, G., SILANIKOVE, N., MERIN, U. Estimate of milk and curd yield loss of sheep and goats with intrammamary infection and its relation to somatic cell count. Small Ruminant Research, v. 74, p. 221-225, 2008.

MALHER, X., SEEGERS, H., BEAUDEAU, F. Culling and mortality in large dairy goat herds managed under intensive conditions in western France. Livestock Production Science, v. 71, p. 75-86, 2001.

MCCARTHY, F.D., LINDSEY, J.B., GORE, M.T., NOTTER, D.R. Incidence and control of subclinical mastitis in intensively managed ewes. Journal of Animal Science, v. 66, p. 2715-2721, 1988.

MELO, C.B., ALMEIDA, B.M., OLIVEIRA, A.A., AZEVEDO, H.C., MELO, L.S.S., MATA, S.S. Avaliação de uma metodologia profilática contra a mastite clínica em ovelhas da raça Santa Inês. Arquivo Brasileiro de Medicina Veterinária e Zootecnia, v. 60, p. 1011-1013, 2008.

MELO, L.S.S., CASTRO, M. B., LEITE, R. C., MOREIRA, E. C., MELO, C. B. Principais aspectos da infecção por Leptospira sp em ovinos. Ciência Rural, v. 40, p. 1235-1241, 2010.

NSW AGRICULTURE. How to tell the age of sheep. Agfact A3.0.1, Division of Animal Production (Reviewed October 2003). New South Wales Department of Agriculture, Australia. 2003. Disponível em http://www.dpi.nsw.gov.au/_data/assets/pdf_file/0004/17 9797/aging-sheep.pdf Acessado em 12 de janeiro de 2007.

RADOSTITS, O.M., GAY, C.C., HINCHCLIFF, K.W., CONSTABLE, P.D. Veterinary Medicine. A textbook of the diseases of catle, horses, sheep, pigs, and goats. $10^{\mathrm{a}}$ ed., Saunders-Elsevier, Philadelphia, USA, 2007.

RYU, E. Rapid mocroscopic agglutination test for leptospira based on $400 \mathrm{X}$ magnification of darkfield examination. Taiwan Journal Veterinary Medical Animanimal Husbandry, n. 17, p. 1-9, 1970.

SAGLAM, Y. S.; YENER, Z.; TEMUR, A.; YALCIN, E. Immunohistochemical detection of leptospiral antigens in cases of naturally occurring abortions in sheep. Small Ruminant Research, v. 74, p. 119-122, 2008. 

SAMPAIO, I.B.M. Estatística aplicada à
experimentação animal. FEP Editora: 1998. $221 \mathrm{p}$.

SARATSIS, P.; LEONTIDES, L., TZORA, A.; ALEXOPOULOS, C.; FTHENAKIS, G. C. Incidence risk and aetiology of mammary abnormalities in dry ewes in 10 flocks in Southern Greece. Preventive Veterinary Medicine, v. 37, p. 173-183, 1998.

SAS INSTITUTE. SAS statistical package for Windows v. 8.0. SAS Institute, Cary, NC, 1999.

THRUSFIELD, M. Epidemiologia Veterinária. 2 ed., Ed. Rocca, São Paulo, 572p., 2004.
TORRES-HERNANDEZ, G., HOHENBOKEN, W. Genetic and environmental effects on milk production, milk composition and mastitis incidence in crossbred ewes. Journal of Animal Science, v. 49, p. 410-417, 1979.

TURKUTANIT, S. S.; SAGLAM, Y. S.; ARSLAN, M. O.; BOZOGLU, H.; DINLER, U. Etiopathologically investigations of blood protozoa and leptospirosis in sheep and cattle with icterus. Journal Etlik Veterinary Microbiology, v. 13, p. 45-55, 2002.

Protocolado em:05 maio 2010. Aceito em: 11 maio 2012 